\title{
Efficacy and safety of a conversion from the
}

\section{original tacrolimus and mycophenolate mofetil to the generics $\operatorname{Tacpan}^{\circledR}$ and Mowel $^{\circledR}$ after liver transplantation}

\author{
This article was published in the following Dove Press journal: \\ Drug Design, Development and Therapy \\ 17 November 2015 \\ Number of times this article has been viewed
}

Johanna Vollmar,' Maren

Christina Bellmann,' Felix

Darstein,' Maria Hoppe-

Lotichius, ${ }^{2}$ Jens Mittler, ${ }^{2}$

Michael Heise, ${ }^{2}$ Bernd

Rüttger, ${ }^{3}$ Veronika Weyer, ${ }^{4}$

Anca Zimmermann, ${ }^{5}$ Hauke

Lang, ${ }^{2}$ Peter R Galle,' Tim

Zimmermann'

'First Department of Internal Medicine, Gastroenterology and Hepatology, Johannes Gutenberg University, Mainz, Germany;

${ }^{2}$ Department of Hepatobiliary and Transplantation Surgery, Johannes

Gutenberg University, Mainz,

Germany; ${ }^{3}$ Panacea Biotec Germany

$\mathrm{GmbH}$, Munich, Germany; ${ }^{4}$ Institute

for Medical Biostatistics, Epidemiology

and Informatics (IMBEI), University

Medical Center, Johannes Gutenberg

University, Mainz, Germany; ${ }^{5}$ First

Department of Internal Medicine,

Endocrinology and Metabolic

Diseases, Johannes Gutenberg

University, Mainz, Germany
Correspondence: Tim Zimmermann First Department of Internal Medicine, Gastroenterology and Hepatology, Johannes Gutenberg University Langenbeckstraße I, 55I3I Mainz, Germany

$\mathrm{Tel}+496131170$

Fax +49 6I3। I7476075

Email tim.zimmermann@unimedizinmainz.de
Background: Expensive pharmaceuticals are a major reason for cost intensive health care systems. Long-term immunosuppressive therapy plays a relevant role after organ transplantation. Patents of original drugs have expired and cheaper products are available. Little data are available regarding efficacy and safety of generic immunosuppressive agents.

Methods: In this prospective study, 25 patients, who were clinically stable for a minimum of 2 years after liver transplantation, were converted from the original formulations of tacrolimus (TAC) and mycophenolate mofetil to the generics $\operatorname{Tacpan}^{\circledR}$ (TAP) and Mowel ${ }^{\circledR}$ (MOW). Patients were followed-up for 6 months. Results were compared retrospectively to 25 age- and sex-matched controls treated with the original brands.

Results: In the matched-pair analysis of TAC trough level/dose ratio, no significant difference was found between TAP/MOW and TAC/mycophenolate mofetil groups. No acute rejection occurred in either group. In total, 17 patients reported mild side effects in the TAP/MOW group. The most common side effects were gastrointestinal symptoms. Intra-individual analysis of costs revealed a considerable cost reduction in the TAP/MOW group (in median $25.03 \%$; $P<0.001)$.

Conclusion: In summary, the use of the generics TAP/MOW is effective and seems to be safe and cost-efficient in stable liver-transplantation patients.

Keywords: immunosuppression, liver transplantation, generics, tacrolimus, mycophenolate mofetil

\section{Introduction}

Expensive pharmaceuticals are one of the most important causes for cost intensive health care systems. Hereby, immunosuppression approved for the prevention of rejection following solid organ transplantation (SOT), plays a relevant role. Patents of original drugs of tacrolimus (TAC) and mycophenolate mofetil (MMF) have expired and cheaper products are available. Due to safety reasons and the notable risk of rejection, transplant centers and outpatient clinics hardly prescribe generics. To date only little data exist evaluating efficacy and safety of generics after SOT.

Generic formulations of TAC have been tested in various studies in different countries. $^{1-10}$

The majority of studies refers to the use of generic immunosuppression after kidney transplantation and contains a lot of circumstantial and weak evidence that it is safe to convert patients from original products to generic drugs, which often only looks at graft survival. 
For example, two studies with altogether 424 kidneytransplant patients in India receiving generic TAC by Panacea Biotec, New Delhi, India $\left(\right.$ PanGraf $^{\circledR}$ ) equal to Tacpan ${ }^{\circledR}$ (TAP) resulted in an overall survival of $94.2 \%$ and $95 \%$. The incidence of acute rejection was $3.87 \%$ and $4 \%$. The results were comparable to those obtained with innovator TAC in literature, with considerable cost savings. ${ }^{1,2}$

However in a study from Momper et al the conversion from original TAC to a generic by Sandoz (Holzkirchen, Germany) resulted in a significantly lower mean TAC blood concentration/dose ratio and a slightly lower blood concentration of TAC in 48 liver and 55 kidney-transplant patients. No alterations in transplant function were found and no rejections occurred. ${ }^{3}$

Alloway et al, Marfo et al, and a Korean prospective, randomized study showed in altogether 270 kidney-transplant patients, that a generic TAC formulation has a similar pharmacokinetic profile as the reference product and most differences in the safety and effectiveness of the medications were not considered clinically relevant. ${ }^{4-6}$

A prospective Swedish study by Rosenborg et al proclaimed that stable kidney-transplant patients $(n=42)$ treated with Prograf ${ }^{\circledR}$ can be converted to Tacrolimus Sandoz ${ }^{\circledR}$ if trough concentrations of TAC and plasma creatinine levels are closely monitored. The conversion resulted in savings, despite costs for extra monitoring. ${ }^{7}$

For MMF Rutkowski et al and Gonzalez-Martínez et al found a similar graft and patient evolution in altogether 89 kidney-transplant patients treated with generic MMF in comparison to 273 patients receiving the original drug. ${ }^{8,9}$

The use of generic TAC Adoport ${ }^{\circledR}$ by Sandoz after liver transplantation (LT) has been analyzed in 48 LT patients by Dannhorn et al in England. They found Adoport ${ }^{\circledR}$ safe and effective regarding rejection, sepsis, cytomegalovirus infection, transplant function, and dose/blood concentration compared to Prograf ${ }^{\circledR}$ when used de novo in LT patients. TAC costs were significantly reduced by the use of Adoport ${ }^{\circledR} .{ }^{10}$

A prospective Korean multicenter study by Kim et al showed that generic MMF My-rept ${ }^{\circledR}$ (Chong Kun Dang Pharmaceutical Co., Seoul, Korea) was comparable in efficacy to the brand-name drug in 154 clinically stable, adult liver-transplant recipients. ${ }^{11}$

Sudhindran et al showed, in a study with 59 liver-transplant patients, that the use of generic products for immunosuppression (PanGraf ${ }^{\circledR}$ and Mycept ${ }^{\circledR}$ by Panacea Biotec) after LT is effective and safe. ${ }^{12}$

In Germany, a retrospective single-center study on the conversion to generic cyclosporine A (CSA) in stable patients after heart transplantation by Kraeuter et al demonstrated no statistically significant differences in the CSA dose-normalized trough levels after a conversion to generic CSA Equoral ${ }^{\circledR}$ (Ivax Pharmaceuticals s.r.o., Troppau, Czech Republic). ${ }^{13}$

In the US, Spence et al retrospectively analyzed a large cohort of 234 renal, liver, and heart transplant recipients. Their data showed that use of generic TAC results in trough concentrations that are comparable to the brand-name drug. ${ }^{14}$

In summary, only a few studies investigated detailed information such as immunosuppressants' trough levels and graft function and many questions about the use of generic drugs remain. ${ }^{15}$

For example, therapeutic equivalence is still not proven as the studies for the approval were performed on healthy subjects showing only bioequivalence. For the approval of generics in Europe and the US bioequivalence studies on a small number of healthy volunteers without the concomitant medications used in the clinical routine of solid organ transplant recipients are required..$^{16-18}$

The European society for organ transplantation demands data on efficacy and safety of the new generic products for immunosuppression. ${ }^{16}$

Therefore the aim of this prospective single-center study was to investigate efficacy and safety of the generic TAC and MMF formulations TAP (Panacea Biotec) and Mowel ${ }^{\circledR}$ (MOW) (Tecnimede, Abrunheira, Portugal) in comparison to the original Prograf ${ }^{\circledR}$ or Advagraf ${ }^{\circledR}$ (TAC) (Astellas Pharma Inc., Tokyo, Japan) and Cellcept ${ }^{\circledR}$ (MMF) (Hoffman-La Roche Ltd., Basel, Switzerland) in stable LT patients.

TAP and MOW were approved in Germany in July and November 2011. This was the latest approval of generic immunosuppressants after LT when this study was planned. Several generic formulations were approved in Germany before.

Most existing data refer to generic immunosuppression after kidney transplantation and data on generic immunosuppressants after LT are urgently needed. Our pilot study investigated a complete conversion of original immunosuppression to generic formulations after LT. We focused on relevant information such as immunosuppressants' trough levels and graft function, not only overall and graft survival.

\section{Patients and methods \\ Study design}

Adult patients, who underwent LT between 1998 and 2011 at the liver transplant center of the university of Mainz, and who were followed-up in our outpatient clinic, were screened 
for their immunosuppression $(n=375)$. Of this cohort 117 patients received immunosuppression with TAC and MMF. Patients were asked to participate in the study during routine follow-up visits in our outpatient clinic. In total, 95 patients were asked to join the generic group of whom 25 agreed to participate. Forty-six patients declined, 24 patients did not answer (Figure 1).
Finally, 25 patients who were clinically stable for a minimum of 2 years after LT were treated with a combination of the generic immunosuppression TAP (aim trough level 3-7 ng/mL) and MOW (500 mg twice daily) and were monitored prospectively for 6 months between November 2012 and October 2014. Patients could leave the study at any time. TAC and MMF were switched 1:1 to TAP and

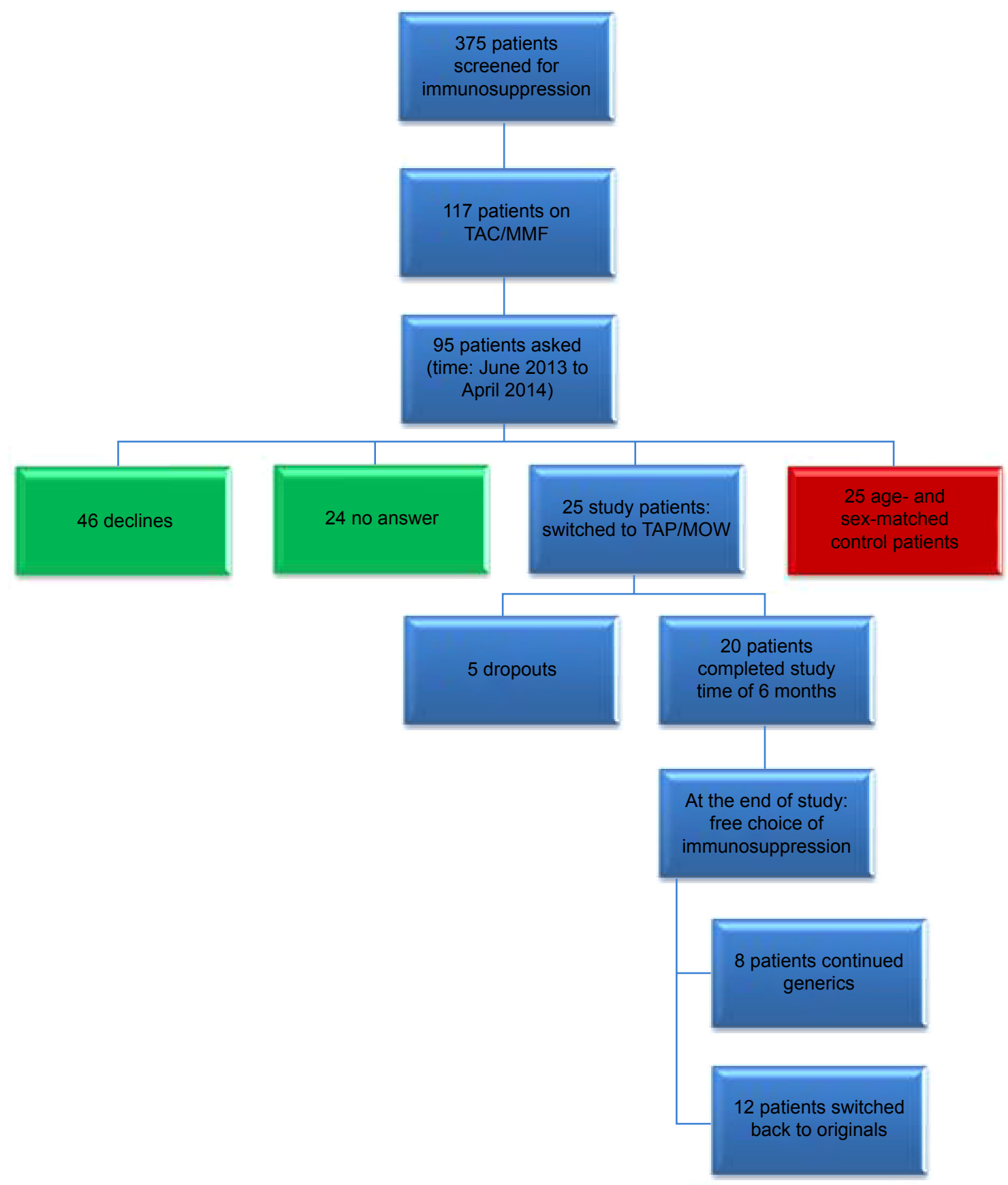

Figure I Study design.

Notes: After screening 375 liver-transplant patients for their immunosuppression 25 patients were switched to the generics Tacpan ${ }^{\circledR}$ (TAP) and Mowel ${ }^{\circledR}$ (MOW) for 6 months. Five patients dropped out due to mild adverse events. At the end of the study patients were free to continue TAP/MOW (eight patients) or to switch back to the original preparations ( 12 patients).

Abbreviations: TAC, tacrolimus; MMF, mycophenolate mofetil. 
MOW. Advagraf ${ }^{\circledR}$ dose was considered as daily dose and converted to TAP twice daily. TAC trough levels, transplant and kidney function, and side effects were investigated 0,3 , and 6 months after conversion to TAP and MOW in the outpatient clinic of the university transplant center Mainz. TAC trough levels, transplant and kidney function, and costs were compared retrospectively to 25 age- and sex-matched control patients treated with the originals Prograf ${ }^{\circledR}$ or Advagraf ${ }^{\circledR}$ and Cellcept $^{\circledR}$. Many patients did not agree to take generics but agreed to serve as a control. Since this study is not randomized, the 25 controls were recruited from the whole cohort excluding the 25 patients on generics. At the end of the study patients were free to switch back to their former medication or keep the generics.

Assessment was performed in concordance with consolidated standards of reporting trials (CONSORT) criteria, although this study was not a randomized controlled trial. ${ }^{17}$

\section{Safety and efficacy}

Graft and kidney function, TAC trough levels as well as electrolytes and blood count were measured by standard chemical analysis. Patient and graft survival were assessed.

\section{Costs}

Daily costs for immunosuppressive drugs for each patient were calculated on the basis of "red list prices", the German catalog listing prices for pharmaceuticals.

\section{Adverse events}

Side effects were assessed by the physician in charge and additionally with questionnaires that patients had to answer at the beginning of the study, 3 months after conversion to the generics, and at the end of the study. Here gastrointestinal (GI), neurological, cardiocirculatory, and dermatological side effects as well as infections and general condition were assessed in three categories of severity: mild, moderate, and severe. Finally, adverse events were categorized in accordance to the World Health Organization (WHO) severity scale. $^{19}$

\section{Inclusion and exclusion criteria}

We included patients who were clinically stable without complications or hospitalizations and received TAC $+\mathrm{MMF}$ during the last 2 years after LT. Only patients with normal graft function and without pathological findings (rejection episodes, infections, elevated liver enzymes, side effects from the pre-existing medication such as diarrhea, emesis or active gastric ulcer) within the last 2 years were eligible to participate in this study. Patients, of minimum 18 years of age, who agreed to have their clinical data analyzed after written informed consent, were included. Exclusion criteria were previous non-adherence, mental impairment, psychiatric illness, or language problems that prohibited reading and understanding the patient information.

Eligible patients for this study were identified by a database search in our transplant database including all transplant patients at the university transplant center Mainz. After identification of potential candidates fulfilling the in- and exclusion criteria $(n=117)$, patients were prospectively asked and included, when they presented during routine follow-up in our outpatient clinic.

\section{Primary endpoint}

The primary endpoint was the number of biopsy proven acute rejection episodes. Criteria for conducting a liver-transplant biopsy were whenever a clinical sign of graft dysfunction (eg, ascites) or laboratory abnormality defined by a more than 2.5-fold increase of liver enzymes or cholestasis parameters (bilirubin) occurred.

\section{Ethics}

The study was performed in accordance with the Declaration of Helsinki, the guidelines for Good Clinical Practice, and the European society for organ transplantation guidelines for the use of generic immunosuppression in SOT. The ethical committee in charge was informed according to the recommendations for planning, conducting, and analyzing observations of applications by the German "Bundesinstitut für Arzneimittel und Medizinprodukte" (BfArM) and the "Paul-Ehrlich-Institute" (ethics no: 837.389 .12 (8490-F); GKV-Spitzenverband no: 2356; BfArM no: 365977/12).

We adhered to the data privacy act and data were collected by case report forms and documentation sheets.

\section{Statistical analysis}

Data management and statistical analyses were performed using the SPSS program (version 22.0; IBM Corporation, Armonk, NY, USA). For descriptive analyses, median and quartiles were calculated for continuous variables. In addition, absolute and relative frequencies were computed for categorical variables.

As variables were not normally distributed, we applied the paired Wilcoxon rank sum non-parametric test to compare generic versus original group. For multiple testing the Friedman analysis of variance was used. All results were interpreted exploratively. No adjustments for multiple testing have been done here. $P$-values are given for descriptive reasons only and should be interpreted with caution. 


\section{Results}

\section{Patient characteristics}

The majority of patients in the TAP/MOW as well as in the TAC/MMF group were male ( $\mathrm{n}=16$ in each group). The median age was $60.5(51.75 ; 64.75)$ years for the TAP/MOW and 61 $(52 ; 64.75)$ years in the TAC/MMF group. The median time after LT was $58(38.25 ; 89)$ months in the generic and 67.5 $(38.25 ; 78.5)$ months in the original group when included in the study. In both groups the majority of patients were on Prograf ${ }^{\circledR}$ when included in the study, the minority took the TAC prolonged release formulation Advagraf ${ }^{\circledR}$. The median body mass index was $26.74(24.56 ; 29.65)$ in the TAP/MOW group and $26.3(23.57 ; 30.35)$ in the TAC/MMF group. The most common primary diseases were alcoholic liver disease, hepatitis B or $\mathrm{C}$ with or without hepatocellular carcinoma in both groups. Two patients in each group underwent re-transplantation. In the TAP/MOW and TAC/MMF groups, seven and 12 patients suffered from diabetes respectively. Only six patients in the TAP/MOW group, but 12 patients in the TAC/MMF group, were affected by chronic kidney disease (Table 1).

\section{Efficacy}

The primary endpoint was the number of biopsy proven acute rejection episodes. During the entire study, no acute rejection or graft loss occurred in the TAP/MOW and the TAC/MMF group.
Regarding secondary endpoints, the TAC trough level/dose ratio showed an inter-individual stability in both groups.

In the matched-pair analysis of TAC trough level/dose ratio, no relevant difference was found between TAP/MOW and TAC/MMF, at the beginning and at the end of the study. The trough level/dose ratio was stable in both groups. The intra-individual course of this ratio also showed stable values under generics in majority of cases (Figure 2).

\section{Changes in TAC trough levels}

TAC trough levels in general were stable under TAP/MOW and TAC/MMF (Figure 3A, B). The majority of patients had trough levels within the range $(3-7 \mathrm{ng} / \mathrm{mL})$, Figure $3 \mathrm{~A}, \mathrm{~B}$. The intra-individual comparison of TAC trough levels at the beginning and at the end of the study showed a slight increase in both groups without statistical significance (in median $+13.89 \%$ in the TAP/MOW and $+5.86 \%$ in the TAC/ MMF group) $(P=0.79)$.

\section{TAC dose and dose adjustment}

TAC dose and necessary dose adjustments in TAP/MOW and TAC/MMF groups are shown in Tables 2 and 3 . In the generic group, five patients required dose adjustments while six patients in the original group had to change their TAC dose. The majority of dose adjustments were dose reductions ( $60 \%$ in the TAP/MOW and $83 \%$ in the TAC/MMF group).

Table I Patient demographics

\begin{tabular}{|c|c|c|}
\hline Patient demographics & TAP/MOW & TAC/MMF \\
\hline \multirow[t]{2}{*}{ Sex } & Male $=16$ & Male $=16$ \\
\hline & Female $=4$ & Female $=4$ \\
\hline Age, median (range) & $60.5(48-70)$ years & $61(47-74)$ years \\
\hline Time after LT, median (range) & $58(24-150)$ months & $67.5(24-170)$ months \\
\hline \multirow[t]{2}{*}{ Original tacrolimus } & Prograf $^{\oplus}=18$ & Prograf $^{\oplus}=11$ \\
\hline & Advagraf ${ }^{\circledR}=5$ & Advagraf ${ }^{\oplus}=9$ \\
\hline Body mass index (BMI) & 27.91 (22.53-38.82) & 27.14 (19.84-38.27) \\
\hline \multirow[t]{9}{*}{ Primary disease } & Alcoholic liver disease $=5$ & Alcoholic liver disease $=3$ \\
\hline & Alcoholic liver disease $+\mathrm{HCC}=3$ & Alcoholic liver disease $+\mathrm{HCC}=3$ \\
\hline & Hepatitis B =2 & Hepatitis B $=5$ \\
\hline & Hepatitis B $+\mathrm{HCC}=2$ & Hepatitis C $=2$ \\
\hline & Hepatitis $\mathrm{C}+\mathrm{HCC}=4$ & Hepatitis B $+\mathrm{HCC}=2$ \\
\hline & Cryptogenic cirrhosis $=1$ & Hepatitis $\mathrm{C}+\mathrm{HCC}=3$ \\
\hline & Primary biliary cholangiopathy $=\mathrm{I}$ & $\mathrm{HCC}=\mathrm{I}$ \\
\hline & Secondary sclerosing cholangitis $=1$ & Familial amyloidosis $=I$ \\
\hline & Polycystic liver disease $=\mathrm{I}$ & \\
\hline Re-transplantation & 2 patients & 2 patients \\
\hline Diabetes mellitus & 7 patients & 12 patients \\
\hline \multirow[t]{3}{*}{ Chronic kidney disease } & Stage $I=2$ & Stage $\mathrm{I}=4$ \\
\hline & Stage $2=2$ & Stage $2=8$ \\
\hline & Stage $3=2$ & \\
\hline
\end{tabular}

Abbreviations: HCC, hepatocellular carcinoma; TAP, Tacpan ${ }^{\oplus}$; MOW, Mowel ${ }^{\oplus}$; TAC, tacrolimus; MMF, mycophenolate mofetil; LT, liver transplantation. 


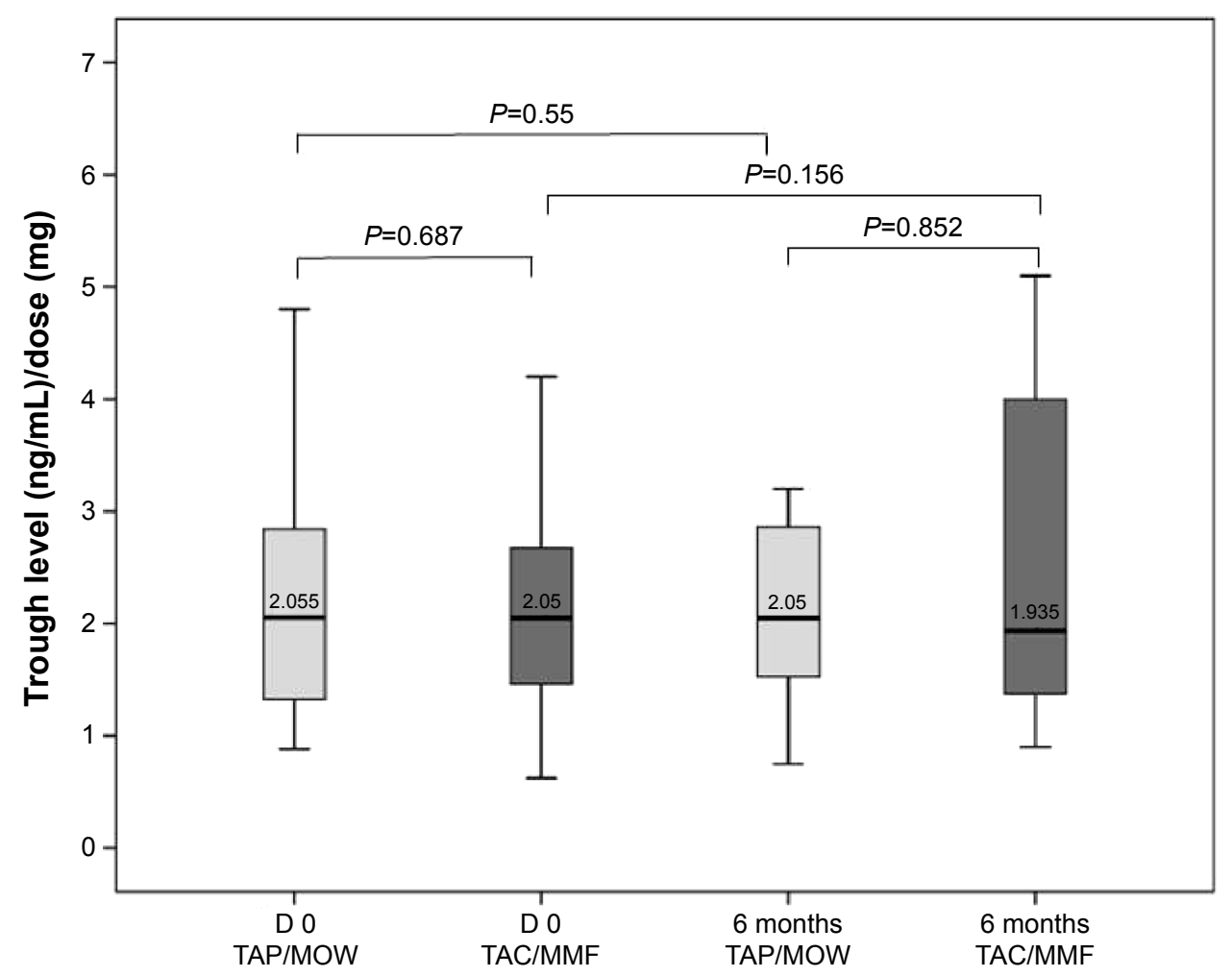

Figure 2 Matched-pair analysis of tacrolimus trough level/dose ratio.

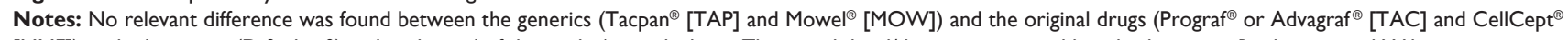
[MMF]) at the beginning (D 0: day 0 ) and at the end of the study 6 months later. The trough level/dose ratio was stable in both groups. $P$-values: paired Wilcoxon-test.

Abbreviations: TAC, tacrolimus; MMF, mycophenolate mofetil.

\section{Safety}

The results of the matched-pair analysis of blood parameters are demonstrated in Table 4. No significant difference was found in the laboratory values between TAP/MOW and TAC/MMF group at the beginning and at the end of the study after 6 months. Survival of patients and transplanted organs was $100 \%$ in both groups, generics and original.
A

TAP

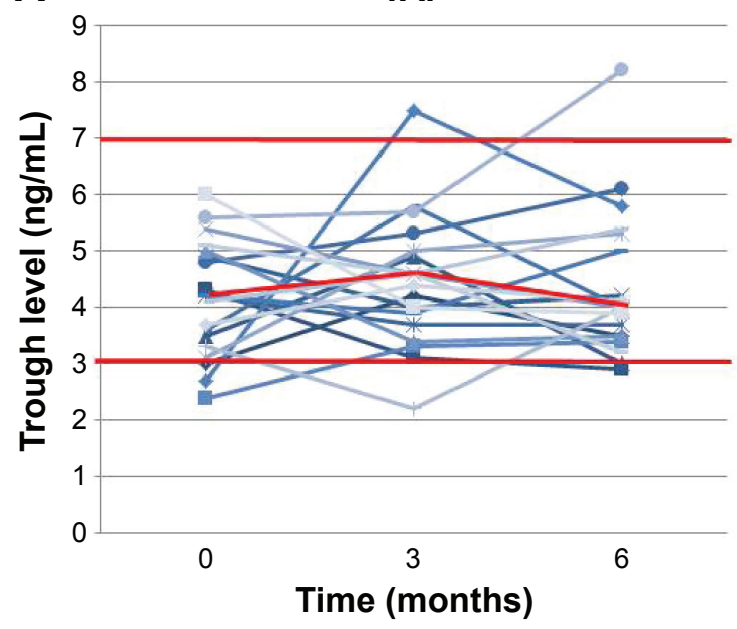

B TAC

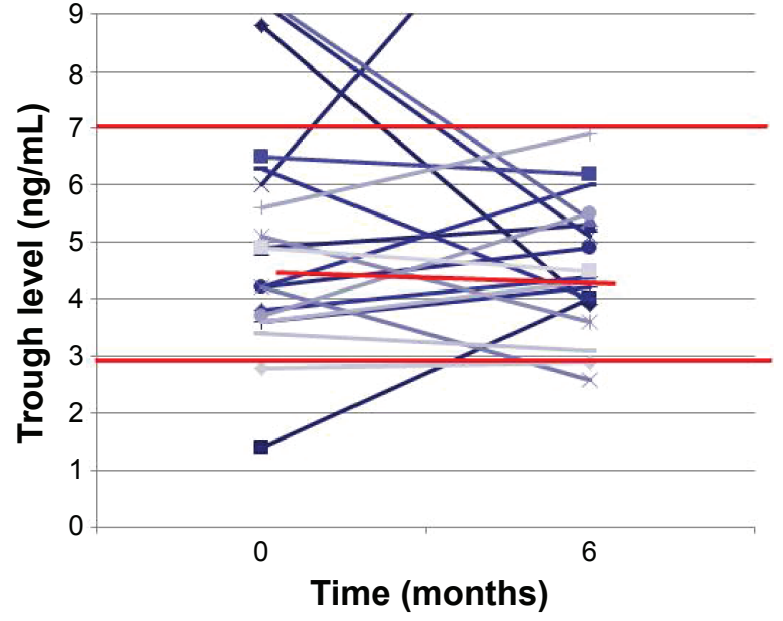

Figure 3 Change in tacrolimus trough level.

Notes: Tacrolimus trough levels were stable in both generic (Tacpan ${ }^{\circledR}[\mathrm{TAP}]$ and Mowe $\left.{ }^{\circledR}[\mathrm{MOW}]\right)(\mathrm{A})$ and original (Prograf ${ }^{\circledR}$ or Advagraf ${ }^{\circledR}[\mathrm{TAC}]$ and CellCept $\left.{ }^{\circledR}[\mathrm{MMF}]\right)$ (B) groups. The majority of patients was within the range of intended trough levels $(3-7 \mathrm{ng} / \mathrm{mL})$ during the study. Trough levels are shown for each patient at different time points. The intra-individual comparison of tacrolimus trough levels at the beginning and at the end of the study showed a slight increase in both groups (in median $+13.89 \%$ in the TAP/MOW and $+5.86 \%$ in the TAC/MMF group) without statistical relevance ( $P=0.79$, paired Wilcoxon-test).

Abbreviations: TAC, tacrolimus; MMF, mycophenolate mofetil. 
Table 2 Tacrolimus dose and dose adjustment (generic group)

\begin{tabular}{|c|c|c|c|c|}
\hline $\begin{array}{l}\text { Patient } \\
\text { number }\end{array}$ & $\begin{array}{l}\text { Dose } \\
\text { D } 0\end{array}$ & $\begin{array}{l}\text { Dose } \\
3 \text { months }\end{array}$ & $\begin{array}{l}\text { Dose } \\
6 \text { months }\end{array}$ & $\begin{array}{l}\text { Dose } \\
\text { adjustment }\end{array}$ \\
\hline I & $3 \mathrm{mg}$ & $3 \mathrm{mg}$ & $3 \mathrm{mg}$ & None \\
\hline 3 & $2 \mathrm{mg}$ & $2 \mathrm{mg}$ & $2 \mathrm{mg}$ & None \\
\hline 4 & $4 \mathrm{mg}$ & $4 \mathrm{mg}$ & $4 \mathrm{mg}$ & None \\
\hline 5 & $2.5 \mathrm{mg}$ & $2.5 \mathrm{mg}$ & $2.5 \mathrm{mg}$ & None \\
\hline 7 & $1.5 \mathrm{mg}$ & $1.5 \mathrm{mg}$ & $1.5 \mathrm{mg}$ & None \\
\hline 8 & $\mathrm{I} \mathrm{mg}$ & $\mathrm{I} \mathrm{mg}$ & $0.75 \mathrm{mg}$ & Reduction \\
\hline 9 & $5 \mathrm{mg}$ & $5 \mathrm{mg}$ & $2 \mathrm{mg}$ & Reduction \\
\hline II & $1.25 \mathrm{mg}$ & $1.25 \mathrm{mg}$ & $1.25 \mathrm{mg}$ & None \\
\hline 12 & $\mathrm{I} \mathrm{mg}$ & I mg & $\mathrm{I}$ mg & None \\
\hline 13 & $\mathrm{I} \mathrm{mg}$ & $\mathrm{I} \mathrm{mg}$ & $\mathrm{I} \mathrm{mg}$ & None \\
\hline 14 & $2 \mathrm{mg}$ & $3 \mathrm{mg}$ & $3 \mathrm{mg}$ & Rise \\
\hline 16 & $4 \mathrm{mg}$ & $4 \mathrm{mg}$ & $4 \mathrm{mg}$ & None \\
\hline 17 & $2 \mathrm{mg}$ & $2 \mathrm{mg}$ & $2 \mathrm{mg}$ & None \\
\hline 18 & $2 \mathrm{mg}$ & $2 \mathrm{mg}$ & $2 \mathrm{mg}$ & None \\
\hline 19 & $4 \mathrm{mg}$ & $4 \mathrm{mg}$ & $2 \mathrm{mg}$ & Reduction \\
\hline 20 & $\mathrm{I} \mathrm{mg}$ & $\mathrm{I} \mathrm{mg}$ & $1.5 \mathrm{mg}$ & Rise \\
\hline 21 & $2.5 \mathrm{mg}$ & $2.5 \mathrm{mg}$ & $2.5 \mathrm{mg}$ & None \\
\hline 23 & $2 \mathrm{mg}$ & $2 \mathrm{mg}$ & $2 \mathrm{mg}$ & None \\
\hline 24 & $2 \mathrm{mg}$ & $2 \mathrm{mg}$ & $2 \mathrm{mg}$ & None \\
\hline 25 & $2 \mathrm{mg}$ & $2 \mathrm{mg}$ & $2 \mathrm{mg}$ & None \\
\hline
\end{tabular}

Notes: Five patients in the generic group $\left(\right.$ Tacpan $^{\circledR}\left[\right.$ TAP] and Mowe $\left.^{\circledR}[\mathrm{MOW}]\right)$ needed dose adjustments. The majority of dose adjustments were dose reductions (D 0: day 0). Dose adjustments are written in bold.

\section{Adverse events and dropout rate}

The dropout rate was $20 \%(5 / 25)$. Five patients left the study early due to adverse events. In total, 17 patients in the TAP/ MOW group had side effects after switching to generics. The most common side effects were GI, but neurological,

Table 3 Tacrolimus dose and dose adjustment (original group)

\begin{tabular}{|c|c|c|c|}
\hline $\begin{array}{l}\text { Patient } \\
\text { number }\end{array}$ & Dose D 0 & Dose 6 months & $\begin{array}{l}\text { Dose } \\
\text { adjustment }\end{array}$ \\
\hline $\mathrm{Ib}$ & $4 \mathrm{mg}$ & $3 \mathrm{mg}$ & Reduction \\
\hline $3 b$ & $0.5 \mathrm{mg}$ & I mg & Rise \\
\hline $4 b$ & $3 \mathrm{mg}$ & $3 \mathrm{mg}$ & None \\
\hline $5 b$ & $3 \mathrm{mg}$ & $2.5 \mathrm{mg}$ & Reduction \\
\hline $7 b$ & $2 \mathrm{mg}$ & I mg & Reduction \\
\hline $8 b$ & $3 \mathrm{mg}$ & $3 \mathrm{mg}$ & None \\
\hline $9 b$ & $2 \mathrm{mg}$ & $2 \mathrm{mg}$ & None \\
\hline $\mathrm{IIb}$ & $1 \mathrm{mg} / \mathrm{l} .5 \mathrm{mg}$ & $1 \mathrm{mg} / \mathrm{l} .5 \mathrm{mg}$ & None \\
\hline $12 b$ & $1.5 \mathrm{mg}$ & I mg & Reduction \\
\hline $13 b$ & $2.5 \mathrm{mg}$ & $2.5 \mathrm{mg}$ & None \\
\hline $14 b$ & $3 \mathrm{mg}$ & $3 \mathrm{mg}$ & None \\
\hline $16 \mathrm{~b}$ & $10 \mathrm{mg}$ & $6 \mathrm{mg}$ & Reduction \\
\hline $17 b$ & $2 \mathrm{mg}$ & $2 \mathrm{mg}$ & None \\
\hline $18 b$ & $2 \mathrm{mg}$ & $2 \mathrm{mg}$ & None \\
\hline $19 b$ & $6 \mathrm{mg}$ & $6 \mathrm{mg}$ & None \\
\hline $20 b$ & $1.5 \mathrm{mg}$ & $1.5 \mathrm{mg}$ & None \\
\hline $21 \mathrm{lb}$ & $2 \mathrm{mg}$ & $2 \mathrm{mg}$ & None \\
\hline $23 b$ & $3 \mathrm{mg}$ & $3 \mathrm{mg}$ & None \\
\hline $24 b$ & $2 \mathrm{mg}$ & $2 \mathrm{mg}$ & None \\
\hline $25 b$ & $2 \mathrm{mg}$ & $2 \mathrm{mg}$ & None \\
\hline
\end{tabular}

Notes: Six patients in the original group $\left(\right.$ Prograf $^{\circledast}$ or Advagraf ${ }^{\circledast}$ [TAC] and CellCept ${ }^{\circledR}$ [MMF]) needed dose adjustments. The majority of dose adjustments were dose reductions ( $\mathrm{D}$ 0: day 0 ). Dose adjustments are written in bold.

Abbreviations: TAC, tacrolimus; MMF, mycophenolate mofetil. psychiatric and dermatological side effects also occurred (Table 5). All the side effects were mild (grade 1-2 of the WHO scale). Five of the 17 patients with side effects left the study due to adverse events and converted back to TAC/ MMF. Patient 2 suffered from nausea and vertigo and left the study after 1 week. Patient 6 left the study after 3 days because of pneumonia with temperature up to 39.5 degree Celsius. Patient 10 received generics for 3 weeks but then stopped because of dysgeusia, paresthesia, headache, gastric pain, and diarrhea. Patient 15 was treated for 4 weeks with TAP/MOW but then left the study because of xerostomia. Patient 22 left the study after 1 week because of pruritus, nausea, meteorism, and reflux.

\section{Costs}

Intra-individual analysis of immunosuppression costs revealed a statistically high cost reduction $(P<0.001)$ in the TAP/MOW group (in median $21.8 \%$ for TAP (Figure $4 \mathrm{~A}$ ) and $29.3 \%$ for MOW (Figure 4B) in comparison to TAC and MMF respectively per day. The combination TAP/MOW saves $25.03 \%$ of the costs per day in comparison to TAC/MMF which equals $4.38 €$ (Figure 4C) based on public list prices.

\section{End of the study}

Twelve patients decided to switch back to TAC/MMF at the end of the study without any particular reason and eight patients continued TAP/MOW (Figure 1).

\section{Discussion}

This is the first study evaluating generic immunosuppression with TAP/MOW in clinically stable liver-transplant patients. In our open-label prospective non-interventional single-center study we found no significant difference in TAC trough level stability, graft and kidney function, and survival between 25 patients treated with the generics TAP/MOW for 6 months and 25 patients (age- and sex-matched controls) receiving the originals TAC/MMF. During the study, no acute rejections occurred in either group. Side effects were mild (WHO grade 1-2). The most common side effects were GI and neurological.

In general, our data are in line with previous studies analyzing the safety and efficacy of different generic immunosuppression after SOT. ${ }^{1-15}$ In this study combination therapy of TAC and MMF was evaluated in accordance with the current standard of decreasing TAC levels with the time after LT to minimize neurotoxicity and renal failure. ${ }^{20}$

In contrast to the findings of Momper et al for the Sandoz generic TAC, trough levels showed a slight increase in both groups without statistical relevance $(P=0.79)$ but the 
Table 4 Matched-pair analysis of blood parameters

\begin{tabular}{|c|c|c|c|c|c|}
\hline & $\begin{array}{l}\text { TAP/MOW } \\
\text { D } 0\end{array}$ & $\begin{array}{l}\text { TAC/MMF } \\
\text { D } 0\end{array}$ & $\begin{array}{l}\text { TAP/MOW } \\
\text { End of study (month 6) }\end{array}$ & $\begin{array}{l}\text { TAC/MMF } \\
\text { End of study (month 6) }\end{array}$ & $\begin{array}{l}\text { P-value } \\
\text { (Friedman analysis) }\end{array}$ \\
\hline $\mathrm{Na}^{+}(\mathrm{mmol} / \mathrm{L})$ & | 40 (|37-|45) & |38.5 (|34-|42) & $|4|(|36-| 46)$ & 140 (136-144) & 0.092 \\
\hline $\mathrm{K}^{+}(\mathrm{mmol} / \mathrm{L})$ & $4.25(3.5-5.7)$ & $4.35(3.7-5.7)$ & $4.3(3.8-5)$ & $4.4(3.6-5.8)$ & 0.289 \\
\hline $\mathrm{Ca}^{++}(\mathrm{mmol} / \mathrm{L})$ & $2.38(2.25-2.61)$ & $2.35(2.2-2.35)$ & $2.4 I(2.2-2.58)$ & $2.4(2.13-2.56)$ & 0.195 \\
\hline AST (U/L) & $27.5(|7-6|)$ & $25.5(18-129)$ & $29.5(18-56)$ & $29(16-34)$ & 0.90 \\
\hline ALT (U/L) & $20(9-11 I)$ & $22(13-120)$ & $24.5(6-8 I)$ & $24.5(11-122)$ & 0.74 \\
\hline $\mathrm{AP}(\mathrm{U} / \mathrm{L})$ & $81.5(35-204)$ & $78(35-130)$ & $82.5(4 I-220)$ & $72.5(42-136)$ & 0.884 \\
\hline$\gamma$-GT $(\mathrm{U} / \mathrm{L})$ & $35(9-154)$ & $29.5(13-134)$ & $32.5(10-206)$ & $31.5(12-167)$ & 0.684 \\
\hline Bilirubin $(\mathrm{mg} / \mathrm{dL})$ & $0.75(0.31-3.86)$ & $0.68(0.26-2.19)$ & $0.76(0.24-2.58)$ & $0.81(0.37-2.15)$ & 0.753 \\
\hline Creatinine $(\mathrm{mg} / \mathrm{dL})$ & $1.24(0.76-2.15)$ & $1.4(0.6-2.25)$ & $1.17(0.78-2.77)$ & $1.36(0.67-2.18)$ & 0.467 \\
\hline Urea (mg/dL) & $19(9-34)$ & $24(9-47)$ & 19.5 (13-48) & $27(9-5 I)$ & 0.694 \\
\hline $\mathrm{HbA}_{\mathrm{lc}}(\%)$ & $5.55(4.9-7.5)$ & $6.5(4.4-11.4)$ & $5.85(5-7.3)$ & $6.55(4.4-7.7)$ & 0.21 \\
\hline Uric acid (mg/dL) & $6.4(2.9-9.5)$ & $6.85(3.3-9.1)$ & $6.8(3.9-9.9)$ & $6.5(3-11.3)$ & 0.819 \\
\hline CRP (mg/L) & I.6 (0.23-23) & $2.45(0.36-32)$ & $1.5(0.2-18)$ & $2.55(0.33-50)$ & $0.24 I$ \\
\hline Quick (\%) & $104(43-125)$ & $104.5(61-120)$ & $105(73-131)$ & $104(89-125)$ & 0.849 \\
\hline Leucocytes (/nL) & $6.17(2.39-9.56)$ & $5.66(2.2-9.8)$ & 6.45 (1.8-9.78) & $6.29(2.3-14.4)$ & 0.44 \\
\hline Thrombocytes (/nL) & I $75(97-34 \mid)$ & $203.5(104-339)$ & $188(94-395)$ & $104(43-125)$ & 0.962 \\
\hline Hemoglobin (g/dL) & $14.85(9.6-17.4)$ & $13.95(10.8-16.8)$ & $14.8(9.5-17.8)$ & $14(10.3-15.6)$ & 0.071 \\
\hline
\end{tabular}

Notes: No relevant difference in blood values between the generic $\left(\right.$ Tacpan $^{\oplus}\left[\right.$ TAP] and Mowel ${ }^{\circledast}[$ MOW] $)$ and the original $\left(\right.$ Prograf $^{\oplus}$ or Advagraf $^{\oplus}\left[\right.$ TAC] and CellCept ${ }^{\oplus}$ [MMF]) group at the beginning ( $\mathrm{D} 0$ : day 0 ) and at the end of the study after 6 months (Friedman analysis). The data is presented as median (range).

Abbreviations: AST, aspartate aminotransferase; ALT, alanine aminotransferase; AP, alkaline phosphatase; $\gamma-\mathrm{GT}$, gamma glutamyltransferase; $\mathrm{Hb} \mathrm{A}_{\mathrm{lc}}$, glycosylated haemoglobin fraction; CRP, C-reactive protein; TAC, tacrolimus; MMF, mycophenolate mofetil.

Table 5 Side effects

\begin{tabular}{|c|c|c|}
\hline Symptom & Frequency & WHO \\
\hline \multicolumn{3}{|l|}{$\overline{\mathrm{GI}}$} \\
\hline Nausea & $20 \%$ & Grade I \\
\hline Gastric pain & $8 \%$ & Grade I \\
\hline Diarrhea & $25 \%$ & Grade I \\
\hline Obstipation & $20 \%$ & Grade I \\
\hline Meteorism & $8 \%$ & Grade I \\
\hline Reflux & $4 \%$ & Grade I \\
\hline \multicolumn{3}{|l|}{ Neurological } \\
\hline Vertigo & $20 \%$ & Grade I \\
\hline Headache & $8 \%$ & Grade I \\
\hline Paresthesia & $4 \%$ & Grade I \\
\hline Insomnia & $4 \%$ & Grade I \\
\hline Petulance & $4 \%$ & Grade I \\
\hline Dysgeusia & $4 \%$ & Grade I \\
\hline \multicolumn{3}{|l|}{ Dermatological } \\
\hline Pruritus & $15 \%$ & Grade 2 \\
\hline Erythema & $8 \%$ & Grade I \\
\hline Oral aphthae & $4 \%$ & Grade I \\
\hline Oral blisters & $15 \%$ & Grade I \\
\hline Xerostomia & $4 \%$ & Grade I \\
\hline Dry nasal mucosa & $4 \%$ & Grade I \\
\hline Unpleasant body odor & $4 \%$ & Grade I \\
\hline Minimal hair loss & $4 \%$ & Grade I \\
\hline \multicolumn{3}{|l|}{ Infections } \\
\hline Temperature $<38^{\circ} \mathrm{C}$ & $4 \%$ & Grade I \\
\hline Temperature $38^{\circ} \mathrm{C}-40^{\circ} \mathrm{C}$ & $4 \%$ & Grade 2 \\
\hline Pneumonia & $4 \%$ & Grade 2 \\
\hline Respiratory infection & $8 \%$ & Grade I \\
\hline Pharynx infection & $4 \%$ & Grade I \\
\hline \multicolumn{3}{|l|}{ Cardiocirculatory } \\
\hline Blood pressure increase & $4 \%$ & Grade I \\
\hline \multicolumn{3}{|l|}{ Other } \\
\hline Reduced general condition & $4 \%$ & Grade I \\
\hline \multicolumn{3}{|l|}{ Serious adverse events } \\
\hline Acute rejection & $0 \%$ & - \\
\hline
\end{tabular}

Note: WHO grading of side effects and frequency after switching from originals to generics.

Abbreviations: Gl, gastrointestinal; WHO, World Health Organization. necessity of dose reduction in three patients in the TAP/ MOW and five patients in the TAC/MMF group to guarantee the intended trough level of $3-7 \mathrm{ng} / \mathrm{mL} .^{3}$

The results of the intra-individual analysis of costs showed a highly relevant cost reduction of $21.8 \%$ for TAC and $29.3 \%$ for MMF by switching to the generics $(P<0.001)$. The real cost reduction is even much higher since this price data are based on the public list price. The exact prices to be paid by health insurers are less due to rebate contracts between manufacturers and health insurers, however these rebates are contractually not to be disclosed by the rebate partners. Blood tests were evaluated for patients treated with generics or originals at the same time points (at 0,3 , and 6 months). Therefore, the costs for visits in our outpatient clinic were comparable in both groups. In case of this study one additional visit was necessary in generic group patients for logistic but not for medical reasons, eg, informed consent needs to be given at least 24 hours before beginning the study.

Our data are in line with the results of Dannhorn et al who demonstrated a significant reduction of costs with generic TAC by Sandoz in kidney-transplant recipients. ${ }^{10}$ Rosenborg et al also found that the conversion from Prograf ${ }^{\circledR}$ to TAC Sandoz ${ }^{\circledR}$ after kidney transplantation brought savings, despite costs for extra monitoring. ${ }^{?}$

In contrast data published by Helderman et al show, that in de novo renal transplant recipients treated with generic CSA higher total health care costs occurred than in those treated with branded CSA despite initial perceived cost savings. ${ }^{21}$ They concluded that patients who received 


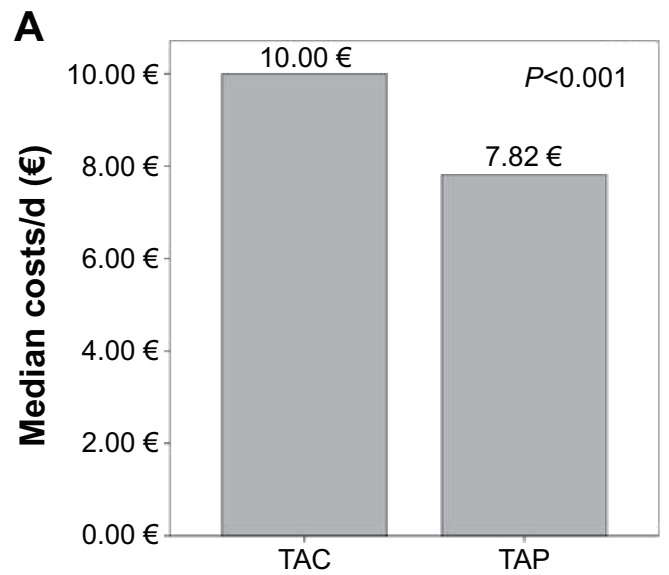

B

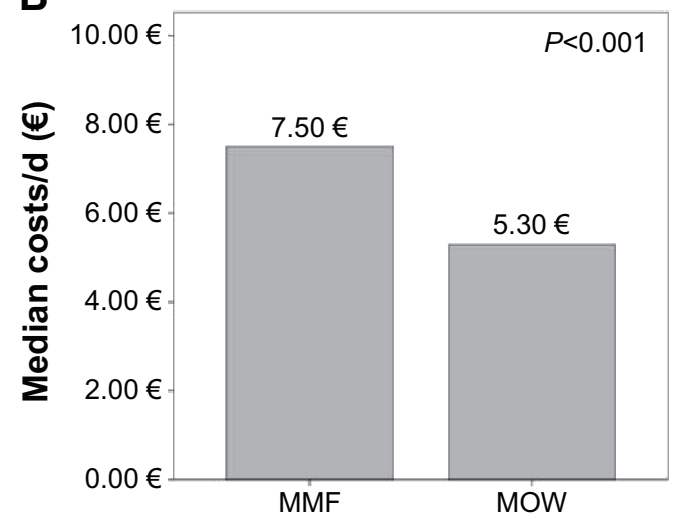

C

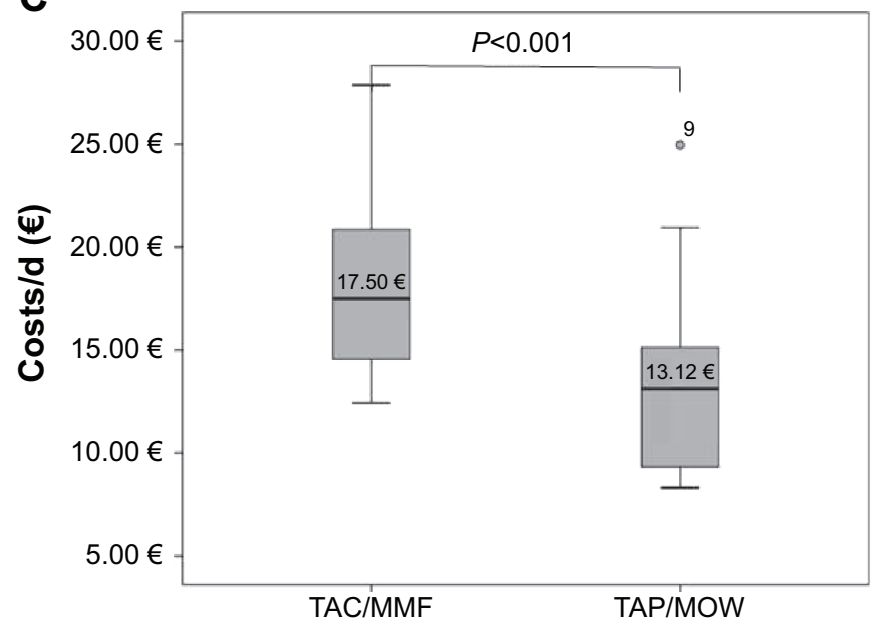

Figure 4 Intra-individual analysis of costs.

Notes: The use of $\operatorname{Tacpan}^{\circledR}$ (TAP) saves in median $21.8 \%$ per day in comparison to Prograf $^{\circledR}$ or Advagraf ${ }^{\circledR}\left(\right.$ TAC) $(P<0.00 \mathrm{I})(\mathbf{A})$. With Mowe ${ }^{\circledR}$ (MOW) a cost reduction of $29.3 \%$ per day was achieved in comparison to CellCept ${ }^{\circledR}$ (MMF) $(P<0.00 \mathrm{I})$ (B). The combination of TAP and MOW saves $4.38 € /$ day in comparison to TAC and MMF $(P<0.00 \mathrm{I})(\mathrm{C})$. $P$-values: paired Wilcoxon-test.

Abbreviations: TAC, tacrolimus; MMF, mycophenolate mofetil; d, day.

generic CSA might need higher doses to maintain the transplanted organ than patients who received branded CSA. ${ }^{14}$

In this study we show that a conversion from original TAC and MMF to the generics TAP and MOW for immunosuppression after LT is safe and cost-effective. The use of generic immunosuppression might relieve our health care system of the burden of high costs caused by expensive original immunosuppressive agents. But first and foremost the drugs need to be effective and safe.

Recruitment for the study was difficult, because many patients have negative attitudes toward generics. Only 25 out of 95 patients agreed to participate in the study. Five patients dropped out due to only mild side effects. These five patients were extremely cautious and sceptic toward generics. They did not want to take the risk of even mild side effects and preferred to take their original medication. At the end of the study the majority of patients decided to switch back to the originals without any particular reason. This might reflect the mistrust toward generics.

\section{Limitations}

The relatively small patient number of 25 participants limits our single-center pilot study. Furthermore it was not a randomized controlled study. There was no blinding and therefore bias due to patients' and investigators' expectancies, especially regarding adverse events, cannot be totally excluded. MMF levels were not measured and no full pharmacokinetic profiles were assessed. Finally the time of observation period might be too short to evaluate long-term effects. The effective cost reduction in reality is higher, however cannot be determined exactly because the rebated prices to be paid by health insurers are not known.

By the end of the study, the approval of TAP in Germany was temporarily suspended by the BfArM due to an ongoing EU referral procedure to investigate the general suspicion against a Clinical Research Organization (CRO). This general view is based on an examination of a few bioequivalence studies where suspicion of Good Clinical Practice violations arose and the subsequent loss of confidence in terms 
of reliability of this CRO, however the TAP studies have explicitly not been part of this examination.

Therefore, informing patients about generics, careful monitoring of trough levels and side effects, and conducting randomized controlled trials with large number of patients are urgently needed.

\section{Conclusion}

In summary, the use of the bioequivalent generics TAP/MOW after LT, while as safe and as effective, is significantly costeffective in comparison to the original drugs. Further studies investigating efficacy and safety of generics in the early and late phase after transplantation are necessary.

\section{Acknowledgments}

We would like to thank all patients, their families, the investigators, and the nurses who participated in this trial. This study was supported by Panacea Biotec Germany GmbH, Munich, Germany and is part of the dissertation of $\mathrm{MB}$.

\section{Author contributions}

$\mathrm{MCB}, \mathrm{JV}$, and TZ wrote the manuscript. TZ and BR designed the study. JV, MCB, FD, MHL, JM, and TZ collected and analyzed data. AZ contributed to the design of the study and critically reviewed the manuscript. VW checked the statistical analysis. HL and PRG critically reviewed and edited the manuscript. All authors contributed toward data analysis, drafting and critically revising the paper and agree to be accountable for all aspects of the work by approving the final paper.

\section{Disclosure}

TZ received travel support from Astellas, Novartis and Roche, consultant and lecture fees from Novartis and Roche and grant support from Panacea and Novartis. BR is an employee at Panacea Biotec Germany GmbH, Munich. Although this study was sponsored and conducted by the University of Mainz, there was a grant support from the generics company Panacea. For full transparency we mention this fact here and in the paper. Panacea was neither involved in the conduction of this study nor in treatment decisions or in the documentation and analysis of data. The authors have no other conflicts of interest in this work.

\section{References}

1. Guleria S, Kamboj M, Chatterjee A, et al. Generic tacrolimus (Pan Graf) in renal transplantation: an experience of 155 recipients in India. Transplant Proc. 2008;40(7):2237-2239.

2. Basu G, Annapandian VM, Mathew BS, et al. Generic Tacrolimus Based Immunosuppression among Renal Allograft Recipients in India. Transplantation. 2012;94(10S):595.
3. Momper JD, Ridenour TA, Schonder KS, Shapiro R, Humar A, Venkataramanan R. The impact of conversion from prograf to generic tacrolimus in liver and kidney transplant recipients with stable graft function. Am J Transplant. 2001;11(9):1861-1867.

4. Alloway RR, Sadaka B, Trofe-Clark J, Wiland A, Bloom RD. A randomized pharmacokinetic study of generic tacrolimus versus reference tacrolimus in kidney transplant recipients. Am J Transplant. 2012; 12(10):2825-2831.

5. Marfo K, Aitken S, Akalin E. Clinical outcomes after conversion from brand-name tacrolimus (prograf) to a generic formulation in renal transplant recipients: a retrospective cohort study. P T. 2013;38(8):484 488.

6. Min SI, Ha J, Kim YS, et al. Therapeutic equivalence and pharmacokinetics of generic tacrolimus formulation in de novo kidney transplant patients. Nephrol Dial Transplant. 2013;28(12):3110-3119.

7. Rosenborg S, Nordström A, Almquist T, Wennberg L, Bárány P. Systematic conversion to generic tacrolimus in stable kidney transplant recipients. Clin Kidney J. 2014;7(2):151-155.

8. Rutkowski B, Bzoma B, Dębska-Ślizień A, Chamienia A. Generic formulation of mycophenolate mofetil (Myfenax) in de novo renal transplant recipients: results of $12-$ month observation. Transplant Proc. 2014;46(8):2683-2688.

9. Gonzalez-MartínezF, Orihuela S, Orihuela N, Manzo L, Nuñez N, Nin M. Descriptive retrospective comparative study between two brands of mycophenolate mofetil used in Uruguay: innovator versus generic (Suprimun). Transplant Proc. 2014;46(9):2996-2999.

10. Dannhorn E, Cheung M, Rodrigues S, et al. De novo use of generic tacrolimus in liver transplantation - a single center experience with one-yr follow-up. Clin Transplant. 2014;28(12):1349-1357.

11. Kim JM, Kwon CH, Yun IJ, et al. A multicenter experience with generic mycophenolate mofetil conversion in stable liver transplant recipients. Ann Surg Treat Res. 2014;86(4):192-198.

12. Sudhindran S, Aboobacker S, Menon RN, Unnikrishnan G, Sudheer OV, Dhar P. Cost and efficacy of immunosuppression using generic products following living donor liver transplantation in India. Indian $J$ Gastroenterol. 2012;31(1):20-23.

13. Kraeuter M, Helmschrott M, Erbel C, et al. Conversion to generic cyclosporine A in stable chronic patients after heart transplantation. Drug Des Devel Ther. 2013;7:1421-1426.

14. Spence MM, Nguyen LM, Hui RL, Chan J. Evaluation of clinical and safety outcomes associated with conversion from brand-name to generic tacrolimus in transplant recipients enrolled in an integrated health care system. Pharmacotherapy. 2012;32(11):981-987.

15. Filler G, Kobrzynski M. The problem with generic immunosuppressants. Pediatr Transplant. 2014;18(6):551-553.

16. van Gelder T; ESOT Advisory Committee on Generic Substitution. European Society for Organ Transplantation Advisory Committee recommendations on generic substitution of immunosuppressive drugs. Transpl Int. 2011;24(12):1135-1141.

17. Schulz KF, Altman DG, Moher D, CONSORT Group. CONSORT 2010 statement: updated guidelines for reporting parallel group randomised trials. Int J Surg. 2011;9(8):672-677.

18. U.S. Food and Drug Administration [homepage on the Internet]. Bioequivalence Recommendations for Specific Products. Department of Health and Human Services. Food and Drug Administration, Center for Drug Evaluation and Research; 2012. Available from: http://www.fda. gov/Drugs/GuidanceComplianceRegulatoryInformation/Guidances/ ucm075214.htm. Accessed October 11, 2015.

19. World Health Organization [homepage on the Internet]. Available from: www.who.int/. Accessed October 11, 2015.

20. Farkas SA, Schnitzbauer AA, Kirchner G, Obed A, Banas B, Schlitt HJ. Calcineurin inhibitor minimization protocols in liver transplantation. Transpl Int. 2009;22(1):49-60.

21. Helderman JH, Kang N, Legorreta AP, Chen JY. Healthcare costs in renal transplant recipients using branded versus generic ciclosporin. Appl Health Econ Health Policy. 2010;8(1):61-68. 


\section{Publish your work in this journal}

Drug Design, Development and Therapy is an international, peerreviewed open-access journal that spans the spectrum of drug design and development through to clinical applications. Clinical outcomes, patient safety, and programs for the development and effective, safe, and sustained use of medicines are a feature of the journal, which has also been accepted for indexing on PubMed Central. The manuscript management system is completely online and includes a very quick and fair peer-review system, which is all easy to use. Visit http://www.dovepress.com/testimonials.php to read real quotes from published authors.

Submit your manuscript here: http://www.dovepress.com/drug-design-development-and-therapy-journal 